Check for updates

Cite this: Chem. Commun., 2022, 58,3905

Received 12th January 2022,

Accepted 20th February 2022

DOI: $10.1039 / \mathrm{d} 2 \mathrm{cc} 00199 \mathrm{c}$

rsc.li/chemcomm

\section{A neutral, acyclic, borataalkene-like ligand for group 11 metals: L- and Z-type ligands side by side $\dagger+$}

\author{
Felix Krämer, ${ }^{a}$ Michael Radius, ${ }^{a}$ Helga Berberich, ${ }^{a}$ Israel Fernández (D) *b and \\ Frank Breher (iD *a
}

The overall neutral $\alpha$-borylated phosphorus ylide $\mathrm{Ph}_{3} \mathrm{PC}(\mathrm{Me}) \mathrm{BEt}_{2}$ behaves like a polar borataalkene and can act as acyclic, ambiphilic $\pi$-type ligand with L- and Z-type functionalities side by side. In the complexes $\left[M X\left\{\eta^{2}-\mathrm{Ph}_{3} \mathrm{PC}(\mathrm{Me}) \mathrm{BEt}_{2}\right\}\right]\left(\mathrm{M}=\mathrm{Cu},(\mathrm{Ag}), \mathrm{Au} ; \mathrm{X}=\mathrm{Cl}, \mathrm{NTf}_{2}\right)$, the bonding is dominated by the highly nucleophilic ylidic carbon atom (L-type ligand). The Lewis acidic boron atom furnishes nonetheless a small but significant bonding contribution (Z-type ligand).

Boron-based ligands for transition metal complexes have received considerable attention for many years. ${ }^{1}$ Among others, one focus of interest refers to ambiphilic chelate ligands featuring an L-type donor entity and a Z-type acceptor unit suitable to stabilize metal $\rightarrow$ boron interactions. ${ }^{2}$ Boron-based $\pi$-ligands have also been studied, most often cyclic structures. ${ }^{3}$ Acyclic boron-based $\pi$-ligands, ${ }^{4}$ however, are relatively scarce and only a few transition metal complexes have been described. ${ }^{5}$ Interests in these types of ligands are rooted in their isoelectronic relationship to olefin ligands (Scheme 1), ${ }^{6}$ which have been studied in great detail during the past decades and are important intermediates in catalytic processes or serve as leaving groups in starting materials and as steering ligands in homogeneous catalysis, for instance. ${ }^{7}$ An inherent feature of anionic borataalkenes ${ }^{8}$ is their flexibility to potentially act as a "classical" $\pi$-ligand according to the well-known Dewar-ChattDuncanson (DCD) model $^{6,7}$ or as ambiphilic L-/Z-type ligand (Scheme 1). ${ }^{9}$

Piers and co-workers presented in 1999 the first example of an electron-poor, "early" $\mathrm{Ta}(0)$ complex featuring an anionic,

\footnotetext{
${ }^{a}$ Institute of Inorganic Chemistry, Karlsruhe Institute of Technology (KIT), Engesserstr. 15, Karlsruhe 76131, Germany.E-mail: breher@kit.edu

${ }^{b}$ Departamento de Química Orgánica I, Facultad de Ciencias Químicas and Centro de Innovación en Química Avanzada (ORFEO-CINQA), Universidad Complutense de Madrid, Madrid 28040, Spain.E-mail: israel@quim.ucm.es

$\dagger$ Dedicated to Prof. Cameron Jones on the occasion of his 60th birthday.

¥ Electronic supplementary information (ESI) available. CCDC 2131093. For ESI and crystallographic data in CIF or other electronic format see DOI: 10.1039/ d2cc00199c
}

$\mathrm{C}_{6} \mathrm{~F}_{5}$-substituted borataalkene ligand (I in Scheme 1), which was synthesized by converting a Ta-bound alkylidene into the $\eta^{2}$-coordinated $\left[\mathrm{H}_{2} \mathrm{C}=\mathrm{B}\left(\mathrm{C}_{6} \mathrm{~F}_{5}\right)_{2}\right]^{-}$ligand. ${ }^{10}$ Quantum chemical calculations predicted that the latter species readily converts to boryl-substituted methyl ligand, most likely due to steric congestion. In 2020, Erker succeeded in isolating complexes of "late", i.e. electron-rich metals bearing an anionic $\mathrm{P} / \mathrm{C}=\mathrm{B}$ chelate ligand (II). ${ }^{11}$ Neutral heteroelement analogs of $\eta^{2}$ bound olefins are, however, very rare. To the best of our knowledge, only one example has been described in the literature. Amgoune and Bourissou described the synthesis and full characterization of the platinum complexes $\left[\left(\mathrm{Ph}_{3} \mathrm{P}\right)_{2} \mathrm{Pt}\right.$ $\left.\left(\eta^{2}-\left\{\mathrm{R}_{2} \mathrm{P}=\mathrm{B}\left(\mathrm{C}_{6} \mathrm{~F}_{5}\right)_{2}\right\}\right)\right]$ (III; $\mathrm{R}={ }^{t} \mathrm{Bu}, \mathrm{Cy}$ ) and performed an indepth quantum-chemical analysis. ${ }^{12}$ Although the BP-based $\pi$ ligand is bound symmetrically, the polar electronic profile of the ligand is also reflected in its partially asymmetric bonding mode featuring characteristics of both a DCD-type $\pi$-ligand and an ambiphilic L-/Z-type ligand.

In this context, we recently reported on a highly polarized $\pi$ bond ${ }^{13}$ consisting of a ylide carbon atom and a boron atom within the $\alpha$-borylated phosphorus ylide $\mathrm{Ph}_{3} \mathrm{PC}(\mathrm{Me}) \mathrm{BEt}_{2}$

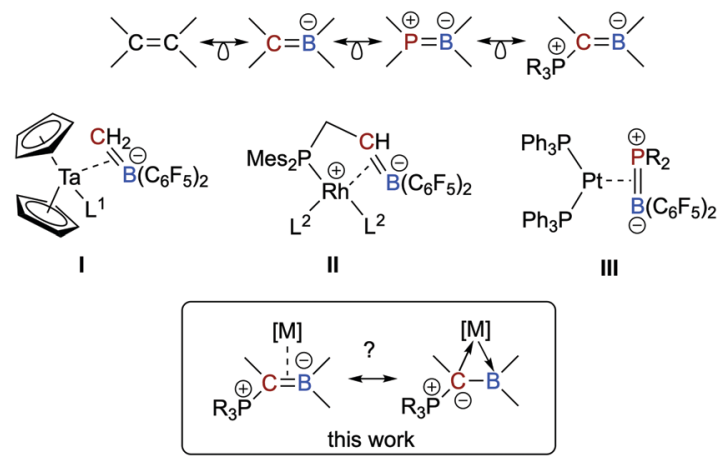

Scheme 1 Isolectronic relationship between olefins and heteroalkenes and selected complexes consisting of anionic and neutral, acyclic boronbased $\pi$-ligands from the literature. Scope of this work. 


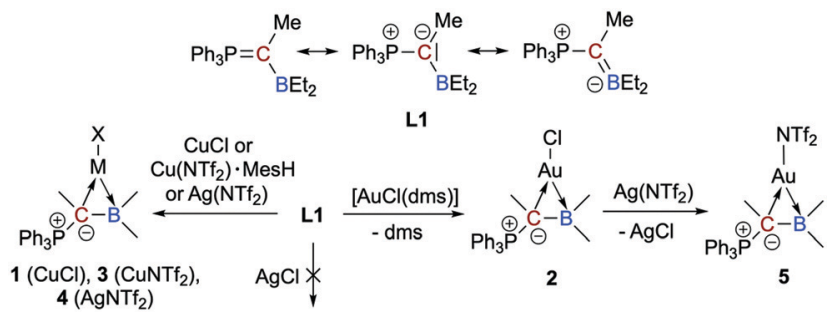

Scheme 2 Treatment of $\mathbf{L} \mathbf{1}$ with various group 11 precursors to furnish the complexes $\mathbf{1 - 5}$

(L1, Scheme 2) ${ }^{14}$ As exemplified in small molecules activation, the competition for the lone-pair of electrons between the boryl $\left(\mathrm{BR}_{2}\right)$ and phosphonyl $\left(\mathrm{PR}_{3}\right)$ substituents results in electronic frustration within this overall neutral, highly polarized borataalkene-like molecule. We now hypothesized that species $\mathbf{L 1}$ would be a promising candidate to act as an acyclic, ambiphilic $\pi$-type ligand with $\mathrm{L}$ - and Z-type functionalities side by side. $^{15}$ Note that a cyclic analog possessing the 9borataphenanthrene anion has been recently published by Martin and co-workers. ${ }^{16}$ Reported herein is the successful realization of our hypothesis by the synthesis and (full) characterization of electron-rich, "late" transition metal complexes of $\mathbf{L 1}$ and a detailed analysis of their bonding situation.

We were able to synthesize the anticipated group $11 \mathrm{com}$ plexes $\left[\mathrm{MCl}\left\{\eta^{2}-\mathrm{Ph}_{3} \mathrm{PC}(\mathrm{Me}) \mathrm{BEt}_{2}\right\}\right](\mathrm{M}=\mathrm{Cu}: \mathbf{1} ; \mathrm{M}=\mathrm{Au}: 2)$ either by reacting $\mathrm{CuCl}$ with $\mathbf{L 1}$ in $\mathrm{CH}_{2} \mathrm{Cl}_{2}(74 \%$ isolated yield) or via the substitution of the $\mathrm{CO}$ in $[\mathrm{AuCl}(\mathrm{CO})]$ with $\mathbf{L 1}$, but only in poor yields (no reaction with $\left.\left[\mathrm{Ph}_{3} \mathrm{PAuCl}\right]\right)$. To our delight, when the gold(I) complex [AuCl(dms)] ( $\mathrm{dms}=$ dimethyl sulfide) is used as a precursor, however, an isolated yield of $91 \%$ for 2 could be achieved (Scheme 2). The mixture of $\mathbf{L 1}$ with $\mathrm{AgCl}$ in 1,2$\mathrm{Cl}_{2} \mathrm{C}_{2} \mathrm{H}_{4}$ at $60{ }^{\circ} \mathrm{C}$ showed no reaction due to insolubility of $\mathrm{AgCl}$.

Suitable single crystals of 2 for X-ray diffraction were obtained by slow solvent evaporation of a saturated $\mathrm{CH}_{2} \mathrm{Cl}_{2}$ solution. The title compound crystallizes in the space group $P 2_{1} / c$ (Fig. 1). Most notably, the P1-C1 (178.2 pm) and the C1B1 bond $(155.2 \mathrm{pm})$ in 2 are considerably elongated as compared to the free pro-ligand $\mathbf{L} 1(171.7 \mathrm{pm}$ and $149.2 \mathrm{pm}$, respectively). This clearly shows that the electron density from the ylidic carbon atom is involved in the $\mathrm{C} 1-\mathrm{Au}$ bond and, thus,

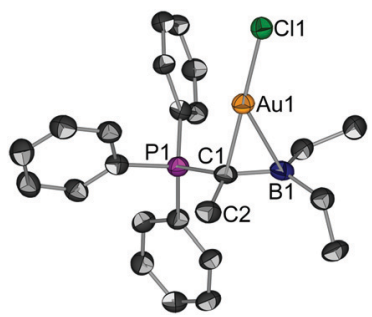

Fig. 1 Molecular structure of 2, thermal ellipsoids drawn at the 30\% probability level. (structural parameters of the second molecule in the asymmetric unit are given in square brackets). Selected bond lengths (pm) and angles ( ${ }^{\circ}$ : Au1-C1 211.3(6), Au1-B1 239.4(8) [241.8(8)], Au1-Cl1 227.74(18), P1-C1 178.2(7), C1-B1 155.2(11), C1-C2 155.2(10); P1-C1Au1 109.0(3), B1-C1-Au1 80.0(4), C1-Au-Cl1 178.2(2) [176.5(2)]. is no longer available for both $\pi$-interactions with $\sigma^{*}(\mathrm{PC})$ or $\mathrm{p}(\mathrm{B})$ orbitals. The gold atom is coordinated in a linear fashion by the ylidic carbon atom and the chloride ligands $(\angle \mathrm{C} 1-\mathrm{Au} 1-$ Cl1 $=178.2^{\circ}$. The C1-Au1-Cl1 axis is slightly tilted towards the boron atom $\left(\angle \mathrm{B} 1-\mathrm{C} 1-\mathrm{Au} 1=80.0^{\circ}\right)$ indicating bonding interaction between the boron center and the gold atom. The short $\mathrm{B}-\mathrm{Au}$ distance of $239.4 \mathrm{pm}$ found in the solid-state is a strong indication for a $\mathrm{Au} \rightarrow \mathrm{B}$ interaction. The distance is in the same region found for gold complexes of polydentate $\mathrm{B} / \mathrm{P}$ ligands. ${ }^{17}$

The ${ }^{1} \mathrm{H}$ NMR spectra of $\mathbf{1}$ and $\mathbf{2}$ in $\mathrm{d}_{8}$-toluene display line broadening at room temperature due to dynamic processes, in particular for the ethyl groups bound to boron. Variable temperature NMR investigations revealed energy barriers of $\sim 16$ (for 1) and $\sim 15$ (for 2) $\mathrm{kcal} \mathrm{mol}^{-1}$ (for further details, see section S5, ESI ). We assumed that this dynamic process is associated with the rotation around the $\mathrm{C}_{\mathrm{ylide}}-\mathrm{B}$ bond. Indeed, density functional theory (DFT) calculations at the dispersioncorrected BP86-D3/def2-TZVPP level (ESI $\ddagger$ ) indicate that the activation barrier associated with the $\mathrm{C}_{\text {ylide }}-\mathrm{B}$ rotation in $\mathbf{1}$ and 2 is 17.5 and $17.8 \mathrm{kcal} \mathrm{mol}^{-1}$, respectively. Both values agree reasonably well with the experimental ones (Fig. S1, ESI $\ddagger$ ). Interestingly, the rotation along the $\mathrm{C}_{\mathrm{ylide}}-\mathrm{B}$ bond has a dramatic impact on the bonding situation in the corresponding transition state TS. As depicted in Fig. S1 (ESI ), the relatively short B-Au distance of $241.4 \mathrm{pm}$ in $\mathbf{2}$ is significantly longer in TS (314.3 pm), thus indicating that the Au $\cdots$ B interaction in the latter saddle-point can be considered as negligible.

Furthermore, the ${ }^{11} \mathrm{~B}$ NMR signal of 2 at a chemical shift of $\delta\left({ }^{11} \mathrm{~B}\right)=53.6 \mathrm{ppm}$ shifted upfield compared to the free proligand $\mathbf{L 1}\left(c f . \delta\left({ }^{11} \mathrm{~B}\right)=56.5 \mathrm{ppm}\right) .{ }^{18}$ This is reminiscent of the ${ }^{11} \mathrm{~B}$ highfield shift of the boron-gold complexes featuring $\mathrm{Au} \rightarrow \mathrm{B}$ interactions (Chart S1, ESI $\$)^{17}$

To check the accessibility of other group 11 complexes, we also prepared the whole series of $\left\{\mathrm{M}\left(\mathrm{NTf}_{2}\right)\right\}$ complexes 3-5 (3: $\mathrm{Cu}, 4: \mathrm{Ag}, 5: \mathrm{Au}$; Scheme 2). It turned out, however, that only highly sensitive, oily products are formed. Due to this, a full characterisation was not possible. We have nevertheless performed comprehensive NMR studies and the results are convincing (e.g. ${ }^{11} \mathrm{~B}$ NMR chemical shifts of $\delta\left({ }^{11} \mathrm{~B}\right)=53.3 \mathrm{ppm}$ for $3,58.5 \mathrm{ppm}$ for $\mathbf{4}, 53.8 \mathrm{ppm}$ for $\mathbf{5}$, respectively, and $\delta\left({ }^{31} \mathrm{P}\right)=$ $31.3 \mathrm{ppm}\left(\mathrm{d},{ }^{2} J_{\mathrm{AgP}}=27,8 \mathrm{~Hz}\right.$ ) for 4 in $\mathrm{d}_{8}$-toluene).

Again, line broadening at room temperature was observed for all complexes due to the dynamic process associated with the rotation around the $\mathrm{C}_{\mathrm{ylide}}-\mathrm{B}$ bond. Variable temperature NMR investigations on 3-5 revealed slightly lower energy barriers of $\sim 15$ (for 3 and 4 ) and $\sim 14$ (for 5) $\mathrm{kcal} \mathrm{mol}^{-1}$.

To further investigate the bonding situation in the newly prepared complexes, we first explored the electronic structure of the pro-ligand L1 with the help of DFT calculations. From the computational studies it becomes clear that pro-ligand L1 is best described by the zwitterionic resonance structure (Fig. S2, ESI $\dagger$ ) with a negative charge on the carbon atom (i.e. ylide) and only to a lesser extent by the borataalkene structure. This is confirmed by comparing the charges and Wiberg Bond Indices of related species (see Table S1, ESI HOMO can be viewed as a lone-pair at the carbon atom, which 
Table 1 Bonding between $M X$ and $\mathrm{Ph}_{3} \mathrm{PC}(\mathrm{Me}) \mathrm{BR}_{2}$ in $\left[\mathrm{MX}\left\{\eta^{2}-\mathrm{Ph}_{3} \mathrm{PC}(\mathrm{Me}) \mathrm{BR}_{2}\right\}\right]$ complexes $\left(\mathrm{M}=\mathrm{Cu}, \mathrm{Ag}, \mathrm{Au} ; \mathrm{X}=\mathrm{Cl}, \mathrm{NTf} \mathrm{f}_{2}\right)\left(\mathrm{EDA}-\mathrm{NOCV}\right.$, values in $\mathrm{kcal}$ mol $\left.{ }^{-1}\right)$, computed at the ZORA-BP86-D3/TZ2P//BP86-D3/def2-TZVPP level

\begin{tabular}{|c|c|c|c|c|c|c|c|c|}
\hline & \multicolumn{3}{|c|}{$\underline{\left.\operatorname{MCl}\left\{\eta^{2}-\mathrm{Ph}_{3} \mathrm{PC}(\mathrm{Me}) \mathrm{BEt}_{2}\right\}\right]}$} & \multicolumn{3}{|c|}{$\underline{\left[\left(\mathrm{MNTf}_{2}\right)\left\{\eta^{2}-\mathrm{Ph}_{3} \mathrm{PC}(\mathrm{Me}) \mathrm{BEt}_{2}\right\}\right]}$} & \multicolumn{2}{|c|}{ 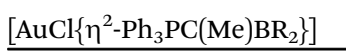 } \\
\hline$\Delta E_{\text {int }}$ & -72.6 & -57.2 & -79.4 & -91.4 & -74.4 & -101.8 & -73.5 & -80.6 \\
\hline$\Delta V_{\text {elstat }}$ & -127.6 & -120.5 & -173.8 & -134.0 & -129.2 & -194.0 & -170.7 & -171.7 \\
\hline$\Delta E_{\text {orb }}$ & -56.0 & -46.5 & -75.0 & -62.6 & -54.4 & -88.4 & -83.0 & -71.4 \\
\hline$\Delta E_{\mathrm{orb}}\left(\rho_{1}\right)$ & -24.6 & -22.4 & -40.0 & -27.6 & -25.6 & -47.6 & -37.7 & -41.4 \\
\hline$r(\mathrm{M}-\mathrm{C}) / \AA$ & 1.979 & 2.178 & 2.132 & 1.971 & 2.175 & 2.100 & 2.144 & 2.126 \\
\hline$r(\mathrm{M}-\mathrm{B}) / \AA$ & 2.318 & 2.556 & 2.414 & 2.322 & 2.501 & 2.447 & 2.258 & 2.589 \\
\hline
\end{tabular}

is slightly delocalized into the adjacent vacant $\mathrm{p}_{z}$ atomic orbital of boron (see below). The latter finding is reflected in the computed C-B Wiberg bond Index of 1.24, which suggests a partial, highly polarized $\mathrm{C}=\mathrm{B}$ bond.

More quantitative insight into the bonding situation of the $\{\mathrm{MCl}\}$ complexes $(\mathrm{M}=\mathrm{Cu}, \mathrm{Ag}, \mathrm{Au})$ can be gained by means of the energy decomposition analysis (EDA) method computed at the relativistic ZORA-BP86-D3/TZ2P//BP86-D3/def2-TZVPP level. From the data in Table 1, columns 2-4, it becomes evident that the main contribution to the bonding between $\mathbf{L} \mathbf{1}$ and $\{\mathbf{M C l}\}$ comes from the electrostatic interactions (measured by the $\Delta V_{\text {elstat }}$ term), which contribute $c a .65 \%$ to the total interaction $\left(\Delta E_{\text {int }}\right)$. This is consistent with the zwitterionic nature of pro-ligand $\mathbf{L} \mathbf{1}$ commented above. Despite that, the orbital interactions $\left(\Delta E_{\text {orb }}\right)$ are also significant, albeit to a lesser extent ( $c a .30 \%)$. In contrast, interactions coming from dispersion forces $\left(\Delta E_{\text {disp }}\right)$ are much less important in the $\mathbf{L 1} \cdots\{\mathrm{MCl}\}$ interaction ( $c a .5 \%)$.

The natural orbital for chemical valence (NOCV) extension of the EDA method was applied next to further partitioning the orbital term into its main pair-wise interactions. According to the EDA-NOCV, two main orbital interactions dominate the total $\Delta E_{\text {orb }}$ term, namely the donation from the lone-pair at the carbon atom to the $\sigma^{*}(\mathrm{M}-\mathrm{Cl})$ and the $\pi$-backdonation from a doubly-occupied $d$ atomic orbital at the transition metal to the vacant $\mathrm{p}_{z}$ atomic orbital of the boron atom, denoted as $\rho_{1}$ and $\rho_{2}$, respectively (see Fig. 2). The $\sigma$-donation $\mathrm{LP}(\mathrm{C}) \rightarrow \sigma^{*}(\mathrm{M}-\mathrm{Cl})$ $\left(\rho_{1}\right)$ is significantly stronger than the $\pi$-backdonation $\left(\rho_{2}\right)$. When inspecting the influence of the coordinated group 11 metal, it becomes clear that $\mathrm{M}=\mathrm{Au}$ leads to stronger interactions in all contributions and that the (hypothetical) silver complexes exhibit the lowest values when compared to $\mathrm{Au}$ or $\mathrm{Cu}$ complexes. This, however, is consistent with recent computations of Bayat et al. ${ }^{19 a}$ on phosphorus ylide complexes of group 11 metals and recent bonding analyses of related $\mathrm{Au}(\mathrm{I})$ complexes. ${ }^{19 b}$ This also correlates with the highest promotion energy for $\mathrm{Ag}(\mathrm{I})$ in the series $\mathrm{Cu}(\mathrm{I})(8.25 \mathrm{eV})<\mathrm{Ag}(\mathrm{I})(9.94 \mathrm{eV})>$ $\mathrm{Au}(\mathrm{I})(7.83 \mathrm{eV})$ and the lowest electron affinity in the series $\mathrm{Cu}(\mathrm{I})$ $(7.72 \mathrm{eV})>\mathrm{Ag}(\mathrm{I})(7.59 \mathrm{eV})<\mathrm{Au}(\mathrm{I})(9.22 \mathrm{eV})$. Moreover, the $\mathrm{Au} \rightarrow$ $\mathrm{p}_{z}(\mathrm{~B})$ backdonation is comparable to that found in those complexes having a single anchor boron ligand (Chart S1, ESI $\$$, which were confirmed to exhibit a significant $\mathrm{Au} \rightarrow \mathrm{B}$
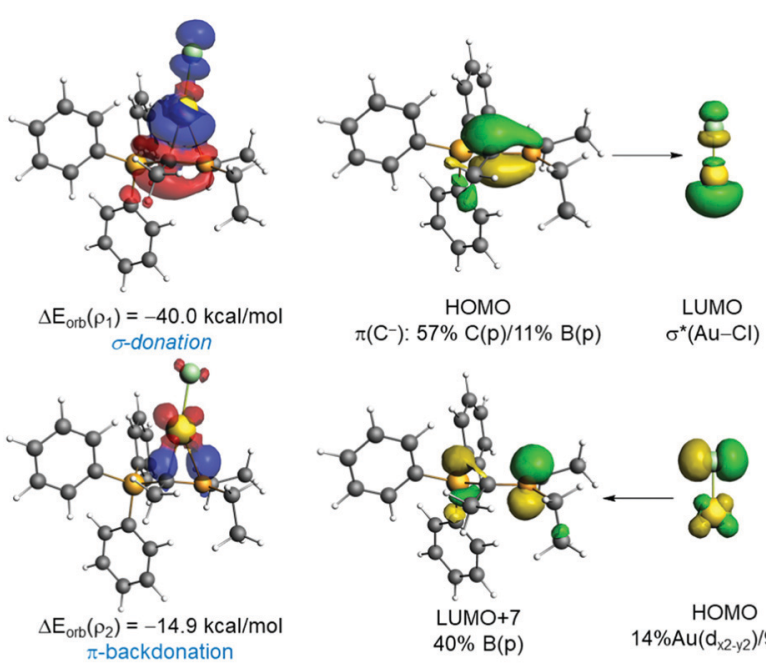

Fig. 2 Deformation densities and associated molecular orbitals of the most important orbital interactions of $\mathbf{2}$ using the fragments $\mathrm{AuCl}$ and $\mathbf{L} \mathbf{1}$ (Table 1) together with the corresponding stabilizing energies $\Delta E_{\text {orb }}\left(\rho_{1}\right)$ and $\Delta E_{\text {orb }}\left(\rho_{2}\right)$. The colour code used to represent the flow of charge is red $\rightarrow$ blue.

interaction. ${ }^{20}$ This backdonation is also validated by the NBO method, which provides a noticeable $\mathrm{Au} \rightarrow \mathrm{B}$ WBI of 0.25 and locates a significant stabilizing delocalization from the doublyoccupied d-atomic orbital of gold to the $\mathrm{p}_{z}$-atomic orbital of boron (associated $\Delta E^{(2)}=-14.2 \mathrm{kcal} \mathrm{mol}^{-1}$ ). Therefore, our EDA-NOCV analysis indicates that the orbital interactions in 2 can be described as two donor-acceptor interactions involving the highly nucleophilic ylidic carbon atom as the dominant ligating atom (L-type ligand) and the Lewis acidic boron atom, which furnishes a weaker yet noticeable bonding contribution as a Z-type ligand. Results above suggest that the $\mathrm{Au} \rightarrow \mathrm{p}_{z}(\mathrm{~B})$ backdonation can be efficiently modulated by modifying either the geometry or the Lewis acidity of the $\mathrm{BR}_{2}$ moiety. For instance, in the rotated TS (Fig. S1, ESI ), the Au-B bond distance is significantly longer than in that in 2 as a consequence of the position of the $\mathrm{p}_{z}$ atomic orbital of boron, which is much less available to accept electron density from the gold atom. As a result, this saddle-point becomes destabilized with respect to 2 and exhibits an almost negligible $\mathrm{Au} \rightarrow \mathrm{p}_{z}(\mathrm{~B}) \pi$ backdonation $\left(\Delta E_{\mathrm{orb}}\left(\rho_{2}\right)<-1 \mathrm{kcal} \mathrm{mol}^{-1}\right)$. 
To check the influence of the Lewis acidity of the $\mathrm{BR}_{2}$ fragment, we attached both a strong electron-withdrawing $\left(\mathrm{CF}_{3}\right)$ and electron-donor (OMe) groups directly to the boron atom. From the data in Table 1, columns 7 and 8, the replacement of the ethyl groups by $\mathrm{CF}_{3}$ significantly enhances the $\mathrm{Au} \rightarrow \mathrm{p}_{z}$ (B) $\pi$-backdonation, which becomes almost twice as strong as that in the parent $2\left(\Delta E_{\text {orb }}\left(\rho_{2}\right)=-25.3 \mathrm{kcal} \mathrm{mol}^{-1}\right)$. This is reflected in a markedly shorter $\mathrm{Au}-\mathrm{B}$ bond $(225.8 \mathrm{pm})$. At variance, the presence of the donor methoxy groups provokes the opposite effect and the $\mathrm{Au} \rightarrow \mathrm{p}_{z}(\mathrm{~B}) \pi$-backdonation becomes weaker $\left(\Delta E_{\text {orb }}\left(\rho_{2}\right)=-9.9 \mathrm{kcal} \mathrm{mol}^{-1}\right)$ whereas the corresponding $\mathrm{Au}-\mathrm{B}$ is much longer (258.9 ppm). We also studied the effect of the M-bound anion and compared $\{\mathrm{MCl}\}$ with $\left\{\mathrm{M}\left(\mathrm{NTf}_{2}\right)\right\}$ (cf. Table 1, columns 5-7). When changing $\mathrm{X}^{-}=$ $\mathrm{Cl}^{-}$to $\left(\mathrm{NTf}_{2}\right)^{-}$, the interaction between the $\{\mathrm{MX}\}$ and the ligand $\mathbf{L 1}$ becomes clearly stronger. This is mainly due to a significant increase in the orbital interactions (the electrostatic term also increases albeit to a lesser extent). In particular, the $\operatorname{LP}(\mathrm{C}) \rightarrow$ $\sigma^{*}(\mathbf{M}-\mathrm{X})\left(\rho_{1}\right)$ interaction becomes stronger because the $\mathbf{M}\left(\mathrm{NTf}_{2}\right)$ fragment is a much better acceptor as compared to $\{\mathrm{MCl}\} .{ }^{20}$ For this same reason, the $\mathrm{Au} \rightarrow \mathrm{p}_{z}(\mathrm{~B}) \pi$-backdonation is slightly weaker.

In summary, this case study clearly depicts that the polar $\pi$ bond of the $\alpha$-borylated phosphorous ylide differs significantly from a $\mathrm{C}=\mathrm{C} \pi$-bond and is even more polar than the phosphinoborane published by Amgoune and Bourissou. ${ }^{12}$ In the $\{\mathrm{MCl}\}$ complexes $\mathbf{1}$ and 2, the highly nucleophilic ylidic carbon atom is the dominant ligating atom (L-type ligand). The Lewis acidic boron atom furnishes a small but significant bonding contribution as a Z-type ligand. Thus, the bonding is asymmetric from both the geometric and the electronic perspectives. The overall neutral, acyclic pro-ligand $\mathbf{L 1}$ indeed behaves like a polar borataalkene ligand, which is induced by the competition for the lone-pair of electrons. Quantum chemical calculations predict that the strength of the $\mathrm{Au} \rightarrow \mathrm{B}$ interaction can be increased by introducing electron-withdrawing groups and decreased by $\pi$ donating substituents on boron. We also provided experimental and computational evidence that the L-type ligand contribution can be increased upon moving from $\mathrm{X}^{-}=\mathrm{Cl}^{-}$to $\left(\mathrm{NTf}_{2}\right)^{-}$. Thus, it appears that the whole continuum between ambiphilic L-/Z-type coordination and DCD-type $\pi$-coordination can be covered by fully exploring the coordination chemistry of variously substituted $\alpha$-borylated phosphorous ylides. Investigations in this direction are currently performed in our laboratories.

This work was supported by the Karlsruhe Institute of Technology (KIT) and the Spanish MCIN/AEI/10.13039/ 501100011033 (Grants PID2019-106184GB-I00 and RED2018102387-T to I. F.)

\section{Conflicts of interest}

There are no conflicts to declare.

\section{Notes and references}

1 Selected reviews: (a) J. T. Goettel and H. Braunschweig, Coord. Chem. Rev., 2019, 380, 184; (b) H. Braunschweig, R. D. Dewhurst and A. Schneider, Chem. Rev., 2010, 110, 3924; (c) J. Takaja, Chem. Sci., 2021, 12, 1964.

2 Selected reviews: (a) G. Bouhadir and D. Bourissou, Chem. Soc. Rev., 2015, 45, 1065; (b) A. Amgoune and D. Bourissou, Chem. Commun., 2011, 47, 859; (c) I. Kuzu, I. Krummenacher, J. Meyer, F. Armbruster and F. Breher, Dalton Trans., 2008, 5836; (d) F. G. Fontaine, J. Boudreau and M. H. Thibault, Eur. J. Inorg. Chem., 2008, 5439; (e) H. Kameo and H. Nakazawa, Chem. - Asian J., 2013, 8, 1720.

3 (a) W. Siebert, Adv. Organomet. Chem., 1980, 18, 301; (b) R. N. Grimes, in Boron-containing Rings Ligated to Metals in Comprehensive Organometallic Chemistry III, ed. R. H. Crabtree, D. M. P. Mingos and C. E. Housecroft, Elsevier Ltd, Oxford, 2007.

4 D. J. H. Emslie, B. E. Cowie and K. B. Kolpin, Dalton Trans., 2012, 41, 1101.

5 Early work on $\pi$-complexes of amino-9-fluorenylideneborane: (a) S. Helm and H. Nöth, Angew. Chem., Int. Ed. Engl., 1988, 27, 1331; (b) S. Channareddy, G. Linti and H. Nöth, Angew. Chem., Int. Ed. Engl., 1990, 29, 199; (c) S. W. Helm, G. Linti, H. Nöth, S. Channareddy and P. Hofmann, Chem. Ber., 1992, 125, 73.

6 R. H. Crabtree, The Organometallic Chemistry of the Transition Metals, Wiley, Hoboken, NJ, 7th edn, 2019, ch. 5.

7 C. Defieber, H. Grützmacher and E. M. Carreira, Angew. Chem., Int. Ed., 2008, 47, 4482.

8 R. J. Maza, J. J. Carbó and E. Fernández, Adv. Synth. Catal., 2021, 363, 2274.

9 (a) M. L. H. Green, J. Organomet. Chem., 1995, 500, 127; (b) M. L. H. Green and G. Parkin, J. Chem. Educ., 2014, 91, 807.

10 (a) K. S. Cook, W. E. Piers and S. J. Rettig, Organometallics, 1999, 18, 1575; (b) K. S. Cook, W. E. Piers, T. K. Woo and R. McDonald, Organometallics, 2001, 20, 3927; (c) K. S. Cook, W. E. Piers and R. McDonald, J. Am. Chem. Soc., 2002, 124, 5411.

11 K. Watanabe, A. Ueno, X. Tao, K. Škoch, X. Jie, S. Vagin, B. Rieger, C. G. Daniliuc, M. C. Letzel, G. Kehr and G. Erker, Chem. Sci., 2020, 11, 7349.

12 A. Amgoune, S. Ladeira, K. Miqueu and D. Bourissou, J. Am. Chem. Soc., 2012, 134, 6560 .

13 D. Munz and K. Meyer, Nat. Rev. Chem., 2021, 5, 422.

14 (a) M. Radius and F. Breher, Chem. - Eur. J., 2018, 24, 15744; (b) M. Radius, E. Sattler, H. Berberich and F. Breher, Chem. - Eur. J., 2019, 25, 12206.

15 To a degree, the boron containing allyl type ligands can be seen as neighboring L- and Z-type ligands: (a) M. W. Drover and J. C. Peters, Dalton Trans., 2018, 47, 3733; (b) F. Jiang, P. J. Shapiro, F. Fahs and B. Twamley, Angew. Chem., Int. Ed., 2003, 42, 2651; (c) K. B. Kolpin and D. J. H. Emslie, Angew. Chem., Int. Ed., 2010, 49, 2716.

16 T. A. Bartholome, A. Kaur, D. J. D. Wilson, J. L. Dutton and C. D. Martin, Angew. Chem., Int. Ed., 2020, 59, 11470.

17 Selected examples: (a) M. Sircoglou, S. Bontemps, M. Mercy, N. Saffon, M. Takahashi, G. Bouhadir, L. Maron and D. Bourissou, Angew. Chem., Int. Ed., 2007, 46, 8583; (b) M. Sircoglou, S. Bontemps, G. Bouhadir, N. Saffon, K. Miqueu, W. Gu, M. Mercy, C.-H. Chen, B. M. Foxman, L. Maron, O. V. Ozerov and D. Bourissou, J. Am. Chem. Soc., 2008, 130, 16729; (c) A. Ueno, K. Watanabe, C. G. Daniliuc, G. Kehr and G. Erker, Chem. Commun., 2019, $\mathbf{5 5}, 4367$.

18 This should not be the case, because upon coordination, the ylidic carbon atom possesses less electron density and the signal should be shifted downfield: $(a)$ H. Nöth and B. Wrackmeyer, Chem. Ber., 1981, 114, 1150; (b) B. Wrackmeyer, Z. Naturforsch., B: J. Chem. Sci., 2015, 70, 421.

19 (a) M. Bayat, A. Sedghi, L. Ebrahimkhani and S. Sabounchei, Dalton Trans., 2017, 46, 207; (b) M. Navarro, J. Miranda-Pizarro, J. J. Moreno, C. Navarro-Gilabert, I. Fernández and J. Campos, Chem. Commun., 2021, 57, 9280.

20 J. J. Cabrera-Trujillo and I. Fernández, Dalton Trans., 2020, 49, 3129. 